\title{
Staff attitudes to a psychiatric hospital closure
}

\author{
Nick Ardagh-Walter, Prakash Naik and David Tombs
}

\begin{abstract}
Many psychiatric hosplitals in the UK have closed. Factors influencing staff morale around the time of a hospital closure will affect the functioning of that institution. This study surveyed staft anxieties, attitudes and expectations in a major psychiatric hosplital three weeks prior to its closure. We found evidence of widespread denial desplte energetic dissemination of information. There were also significant differences between staff groups. Our findings will have implications for the management of future hospltal closures.
\end{abstract}

"We have to get it into our heads that a hospital is like a shell, a framework to contain certain processes. and when the processes are superseded, the shell must, most probably, be scrapped and the framework dismantled" (Enoch Powell, 1961).

In recent years, many psychiatric hospitals have closed and others are due to close. For a hospital to function optimally, the morale and dedication of staff are vital. This is especially important at the time of a hospital's closure. Factors which may have an effect on staff attitudes around the time of a hospital closure will affect the functioning of that institution.

Many studies have examined the feelings of patients regarding the closure of hospitals (Abrahamson \& Brenner, 1982) but only a few have studied the attitudes of the staff. In many of these, the closure experience was not comparable to the closure of psychiatric hospitals in the UK (Dencker, 1989). Others have merely described individual grief processes and reactions in small numbers of staff (Massey, 1991; Turnbull, 1991). Therefore, there is a need for a systematic study of staff in a modern British setting.

We studied the anxieties, attitudes and expectations of staff prior to the closure of Pastures Hospital (a traditional psychiatric hospital); and factors which influence these anxieties, attitudes and expectations.

\section{Background}

Pastures Hospital, Derby, was opened in 1847 as the County Asylum and at its peak had over 1200 beds. In 1988, plans were made to close the hospital. It closed in November 1993 and the in-patients were transferred to a purpose built District General Hospital (DGH) Unit. This closure is closely comparable to the experiences of many other such hospitals in the UK.

From 1990 onwards, management held a series of open meetings in the hospital, to inform staff of the plans. These meetings continued on a monthly basis. Following meetings with union representatives, it was agreed that all staff from Pastures Hospital would be redeployed if they so wished. In 1991 senior management members established and manned an information room on a part-time basis. The Director of Personnel interviewed all nursing staff individually between 1992 and early 1993. During these sessions, she checked the staff's knowledge about the plans, updated them where necessary, elicited individuals' preferences about future employment and discussed the available options. She aimed to maintain an empathic approach in order to promote the ventilation of feelings about the closure process. By June 1993, all except eight staff had been firmly allocated a specific post and had been informed of this. Three weeks before closure, we carried out our survey.

\section{The study}

A questionnaire was designed to measure the following:

- epidemiological data

- length of service at Pastures Hospital

- attitude towards the move

- specific anxieties about the new unit

- expectations about aspects of patient care in the DGH unit

- whether staff had seen the new unit

- timescale over which the information of hospital closure had been provided to the staff.

Permission for the study was granted by the hospital management and senior nursing staff. The questionnaire was distributed to all medical, secretarial and nursing staff $(n=130)$. Data was collated on a computerised database and associations between variables analysed using the $\chi^{2}$ test. 


\section{Findings}

Of the 130 questionnaires sent out 109 were returned, a response rate of $84 \%$.

\section{Predictor variables}

Of the respondents, five were nurses of Grade $G$ and above, 56 nurses of Grade $F$ and below, 36 nursing assistants, nine doctors and three secretaries. The mean age was 37.3 years. There were 31 males and 78 females. Length of service ranged from one to 40 years (mean 11.2 years), with $66 \%$ serving over 5 years. Only 12 of the respondents stated that they had received counselling. The duration of knowledge of the move ranged from 1 month to 99 months (mean=17.9 months, interquartile range 3-24 months) and 37 respondents stated that they had known of it for four months or less. All except one were due to transfer employment to one of three other psychiatric units in the same city. Over half $(57 \%)$ had seen the place that they were moving to.

\section{Outcome variables}

Sixty per cent were looking forward to moving, while only $11 \%$ were not. However, $41 \%$ admitted to being very anxious about the move, 35\% mildly so; $25 \%$ were anxious about patient care; $39 \%$ about the new environment; $10 \%$ for personal reasons; $25 \%$ about new contacts: $38 \%$ about new working conditions; $32 \%$ expected patient care to improve but only $6 \%$ expected it to deteriorate. Over half (51\%) expected the ward environment to improve and only $6 \%$ expected it to worsen; $26 \%$ expected the Occupational Therapy department to improve, and $85 \%$ expected the grounds to be worse.

\section{Associations between variables}

Those serving 11-20 years were significantly more anxious about the move $(P<0.05)$ and the new conditions of work $(P<0.05)$ than those with length of service less than 10 years or more than 20 years. Length of service was not significantly associated with other specific anxieties.

There were no significant differences between men and women in anxieties about the move, patient care, new contracts or the new conditions of work. However, males were significantly more anxious for personal reasons than females $(P<0.01)$.

Those aged under 40 were significantly more anxious about patient care than staff over 40 years $(P<0.05)$. There was no significant association between age and other specific anxieties.

Nurses were significantly more anxious about the move $(P<0.05)$, patient care $(P<0.01)$, the new environment $(P<0.05)$, the new contracts $(P<0.05)$ and new conditions of work $(P<0.01)$. However, they were not significantly more anxious about personal matters.

Of the 12 who had recelved counselling, 10 reported anxiety about the move, compared with 56 of the 97 who had not $(P<0.05)$.

\section{Comment}

Staff who had worked for 11-20 years at the hospital were significantly the most anxious. Dencker's (1989) results differ in that he found staff employed for more than six years to be more anxious. Reasons may include different closure situations, categorisation of the data and areas of anxiety studied. Also, those who had worked for less than 11 years may still have been at an age when they could hope to find another job. while those who had worked for more than 20 years were less anxious as their retirement plans were not severely affected.

In our study, males were more anxious about personal reasons when compared with the women, the reverse of the Swedish findings (Dencker, 1989). These disparate results might be explained by differences in demography and employment situations. The greater anxiety about patient care of those under 40 may be explained by their more recent formal education. making acceptance of established patterns of care less likely.

Nurses as a group were significantly more anxious than other professionals in most areas. One possible reason is that many nurses had spent their entire careers in the same establishment, and were hence more attached to the institution. Also, their contracts had been changed, which was not the case for the other groups.

Only a small proportion of staff acknowledged that they had received counselling, despite the Director of Personnel having personally interviewed all the staff at least once. These interviews were not overtly labelled as counselling sessions, with permission to show their feelings about the impending move. Hence it is possible that the staff did not consider them as such. Also, the staff may not have felt safe in expressing their feelings to a senior member of the management team.

Surprisingly, those who had received counselling expressed more anxiety. Those who express emotion more freely may have done so both in our questionnaire and in their interviews, and would be more likely to consider the interview with the Director of Personnel as a counselling session. We do not believe that this can be taken as evidence of the effectiveness of the 'interview' 
in reducing the anxiety. Our study was not designed to study this aspect.

It is remarkable that so many staff members stated such short duration of knowledge of the move. The process of dissemination of the information began in 1990. All but eight staff had received confirmation of their new post at least four months prior to our survey. Similar results were reported by Massey, who noted initial disbelief among staff. In the Swedish study (Dencker, 1989), a large majority of staff reported receiving little or no information, despite free distribution of periodicals and information meetings. The closure experience could be considered analogous to the stages of a grief process. When information is first disseminated, denial and protest can be expected and it is unlikely that the information will be 'accepted'. Therefore careful timing of the dissemination in conjunction with appropriate counselling is vital, as is accepting that staff may not appear to be wellinformed while still adjusting to a significant loss.

Clearly, certain members of staff are more anxious at times of hospital closure. Many deny that they have been informed of the move. It is recommended that the timing of the dissemination of information is vital if maximum benefit is to be achieved, and that specific counselling sessions be available for all members of staff, but targeted towards the more vulnerable groups. Employees of long-standing institutions may need time before information about a forthcoming closure is fully taken on board. Further research is warranted in this important area.

\section{Achnowledgements}

We would like to thank Maureen Coxon for her help in entering the data, Mr Richard Seed, Chief Executive of South Derbyshire NHS trust for allowing us to do the study and E. Merck for funding the study.

\section{References}

ABRAhamson, D. \& BRENNER, D. (1982) Do long-stay psychiatric patients want to leave hospital? Health Trends, 14, 95-97.

DENCKER, K. (1989) The closure of a major mental hospital: reactions of the psychogeriatric nursing staff. Social Psychiatry and Psychiatric Epidemiology, 24, 156-164.

MASSEY, P. (1991) Institutional loss: an examination of a bereavement reaction in 22 mental nurses losing their institution and moving into the community. Joumal of Advanced Nursing. 16, 573-583.

PowEu, E. (1961) Address to the National Association for Mental Health. In Emerging Patterns for the Mental Health Services and the Public. London: NAMH.

TURNBULL, C. (1991) Death of a hospital. Nursing Times, 87. 32-34.

*Nick Ardagh-Walter, Senior Registrar in Psychiatry, Psychiatric Clinic, B Floor, South Block, University Hospital, Nottingham NG7 2RD; Prakash Naik, Consultant Psychiatrist, Lyndon Clinic, Hobs Meadow, Solihull, West Midlands B92 8PW; and David Tombs, Consultant Psychiatrist, Acute Psychiatric Unit, Derby City General Hospital, Derby DE22 3NE

*Correspondence 